\title{
ERRATUM
}

\section{Continental-scale temperature variability during the past two millennia}

PAGES 2k Consortium

Nature Geoscience 6, 339-346 (2013); published online 21 April 2013; corrected after print 14 May 2013.

In the version of this Progress Article originally published, the references "43-54" cited in the caption of Fig. 4a should have read "43-45". This has been corrected in the PDF and HTML versions. 